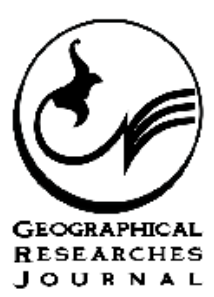

\title{
Identification and Characterization of Dust Source in Khorasan Razavi Province, Iran
}

\section{ART ICLE INF O}

\section{Article Type}

Original Research

\section{Authors}

Pourhashemi S. ${ }^{1} M A$

Amirahmadi A. ${ }^{* 1} P h D$,

Zangane Asadi M.A.1 $P h D$,

Salehi M. ${ }^{2} P h D$
How to cite this article

Pourhashemi S, Amirahmadi A, Zangane Asadi M.A, Salehi M. Identification and Characterization of Dust Source in Khorasan Raz avi Province, Iranl. Geographical Researches Quarterly Journal. 2019;34(1):1-10.
${ }^{1}$ Department of Geomorphology, Geography Faculty, Hakim Sabzevari University, Sabzevar, Iran ${ }^{2}$ Department of statistical, basic Science Faculty, Neyshaboor University, Neyshaboor, Iran

\section{*Correspondence}

Address: Faculty of Geography and Environmental Sciences, Hakim Sabzevari University, Tohid Shahr, Sabzevar, Khorasan Razavi, Iran Phone: +98 (51) 44013378 Fax: +98 (51) 44013271 amirahmadi1388@gmail.com

\section{Article History}

Received: August 06, 2018

Accepted: November 28, 2018

ePublished: February 05, 2019

\begin{abstract}
A B S T R A C T
Aims \& Backgrounds One of the phenomena in arid and semi-arid regions is dust storm. Dust is one of the environmental issues that affects the quality and pollution of the air, human health, soil fertility, visibility, economy, and many social and environmental aspects of the community. The present research was carried out to identify and characterize the dust source in Khorasan Razavi province during 20052016.

Methodology In this study, 65 dust sources in the study area were identified, using MODIS images. Then, the characteristics of these points were studied in terms of soil, slope, elevation, normalized difference vegetation index (NDVI), lithology, and land use.

Findings In the land use area, $63 \%$ of the points were located at the levels related to the poor pastures (23 points) and dry land (18 points). In the slope layer, $43.07 \%$ of the points were located on the $0-2 \%$ floor and in the soil layer, $49.2 \%$ of the points were on the floor of the Eridisol, which included $39.2 \%$ of the area of the area. In the NDVI layer, $98.4 \%$ of points that covered about $99 \%$ of the area of the area was related to the non-vegetation section, and in the layer related to the elevation points, $90 \%$ of the points (60 points) were located in the altitudinal area of $0-1500$. In relation to the lithology of the region, discontinuous sedimentary units with an area of 49.56 had covered about $66.15 \%$ of the points. Conclusion Most of the dust source areas are located in weak pasture and dry land with erosive soil and lithology that has poor vegetation cover.
\end{abstract} Keywords Dust source; Land Cover; NDVI; Khorasan Razavi Province

\section{CIT A T I O N L I N KS}

[Ackerman SA; 1997] Remote sensing aerosols ...; [Baddock MC, et al.; 2011] Geomorphology of the ...; [Boroghani M, et al.; 2017] Dust Source Identification ...; [Bullard J, et al.; 2008] Sub-basin scale dust ...; [Cao H, et al.; 2015] Identification of dust ...; [Crouvi O, et al.; 2012] Multiple dust sources ...; [Dawelbait M \& Morari F; 2012] Monitoring desertification ...; [Ebrahimi Khosfi Z, et al.; 2017] Investigation of the role ...; [Engelstaedter S, et al.; 2003] Controls of dust emissions ...; [Floyd KW \& Gill TE; 2011] The association of land ...; [Goossens D \& Buck B; 2009] Dust dynamics in ...; [Goudie A; 2014] Review Desert dust ...; [Hahnenberger M \& Nicoll K; 2014] Geomorphic and land ...; [Hao X, et al.; 2007] A highperformance ...; [ Jewell PW \& Nicoll K; 2011] Wind regimes and aeolian ...; [Karimi K, et al.; 2011] Dust source identification ...; [Lee J, et al.; 2012] Geomorphic and land ...; [Lee J, et al.; 2009] Land use/land cover and ...; [Lim JY \& Chun Y; 2006] The characteristics of ...; [Lindley TT, et al.; 2011] Proximity meteorological ...; [Maurer T, et al.; 2009] The effect of surface ...; [Miller ME, et al.; 2012] Post-fire land treatments and ...; [Moridnejad A, et al.; 2015] Newly desertified ...; [Mosavi Bayghi M \& Ashraf B; 2012] The study of synoptic patterns ...; [Parajuli Sp \& Zender CS; 2017] Connecting geomorphology ...; [Pourghasemi HR \& Kerle N; 2016] Threats and ...; [Pourhashemi S, et al.; 2015] Analysis relation of vegetation ...; [Prospero JM, et al.; 2002] Environmental characterization ...; [Rashki A, et al.; 2013] Dryness of ephemeral ...; [Rashki A, et al.; 2012] Dust storms and their ...; [Rezazadeh M, et al.; 2013] limatology of the Middle ...; [Rivera Rivera NI, et al.; 2010] Source characteristics of hazardous ...; [Roscovensky JK \& Liou, KN; 2005] Differentiating airborne ...; [Sankey JB, et al.; 2013] Phenologybased, remote ...; [Sissakian V, et al.; 2013] Sand and dust storm ...; [Sweeney MR, et al.; 2011] Quantifying dust emissions ...; [Tan M, et al.; 2014] Intensity of dust storms in ...; [Tsolmon R, et al.; 2008] National security an ambiguous ...; [Vickery K \& Eckardt F; 2013] Dust emission controls on ...; [Walker AL, et al.; 2009] Development of a dust source ...; [Wang X, et al.; 2008] Dust sources in arid and semiarid ... ; [Zobeck T, et al.; 2013] Soil property effects on wind erosion ...; [Zoljoodj M, et al.; 2013] Dust Events in the Western ... 
بيمارىزاى خطرناك به انسان، آلودگى هوا و آسيبرساندن به

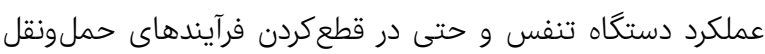

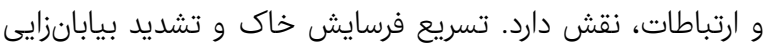

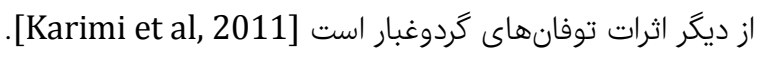

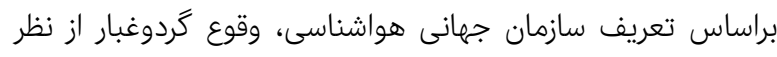

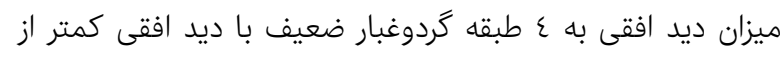

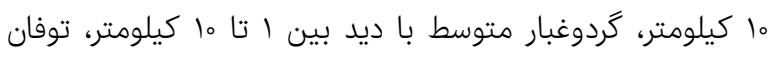

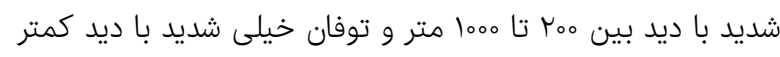

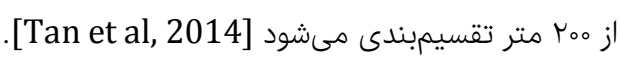

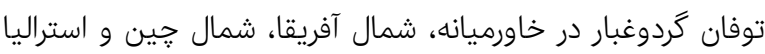

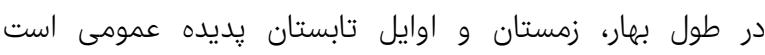

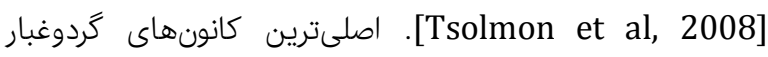

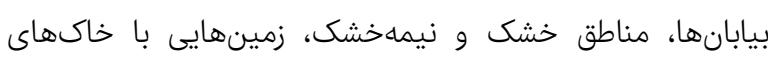

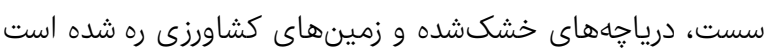

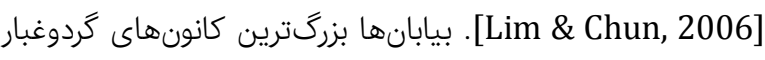
و داراى عوارض زئومورفولوزى با يتانسيل انتشار كردوغبار بالاست [Sweeney et al, 2011]

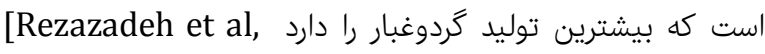

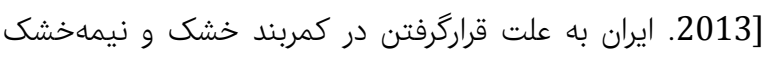

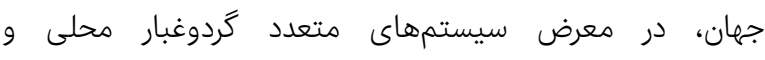
[Rashki et al, 2012; Goudie, 2014; مرامني .Pourhashemi et al, 2015]

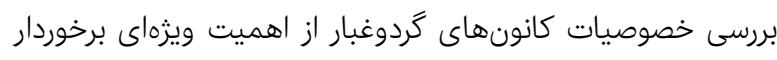

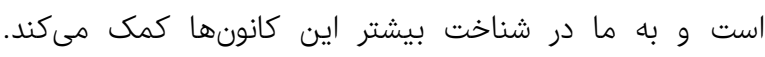

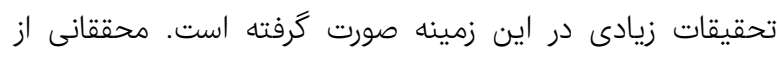

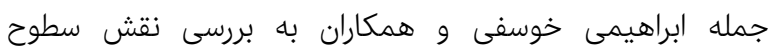

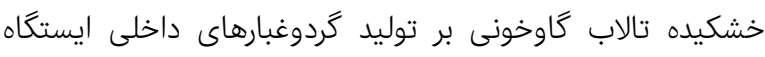

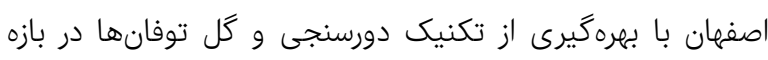

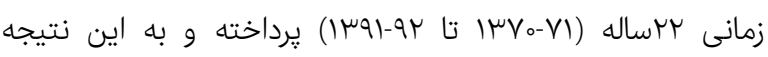

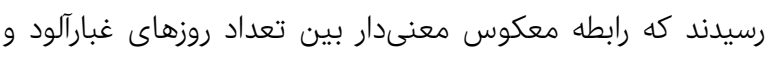

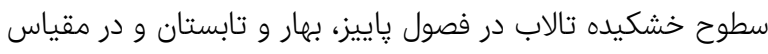

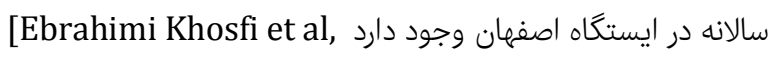

.2017]

بروغنى و همكاران [Beroghani et al, 2017] به شناسايى

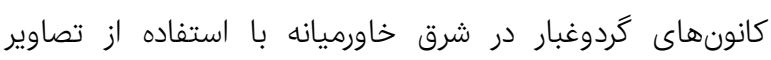

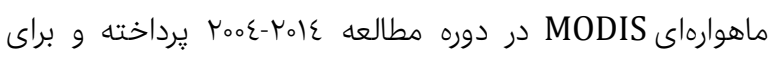

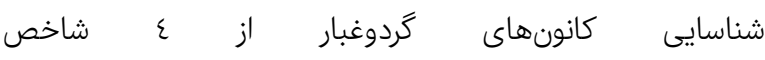

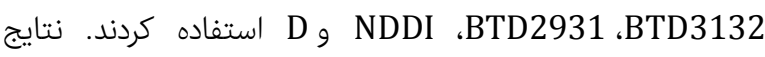

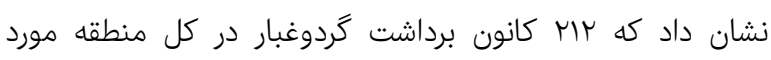

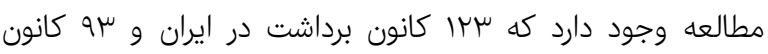

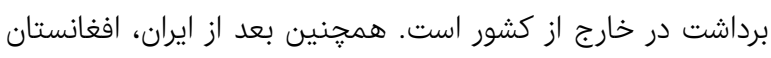

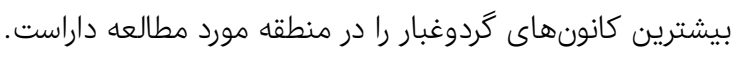

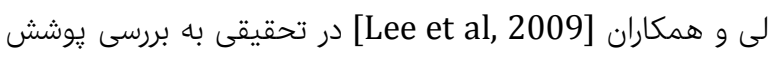

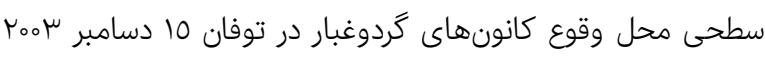

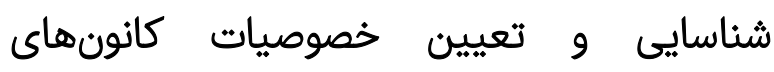 گردوغبار در استان خراسان رضوى}

جكيده اهداف و زمينهها: يكى از رِيديدهاى مناطق خشك و و نيمهاه

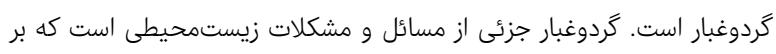

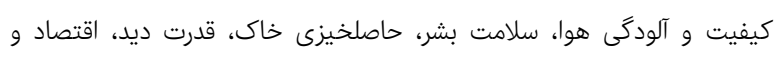

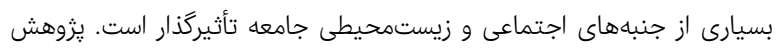

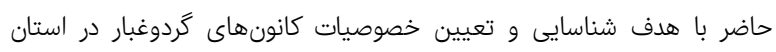

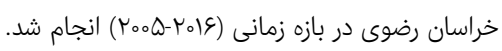

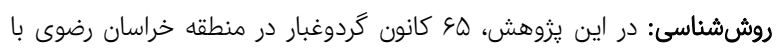

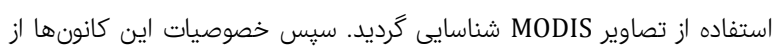

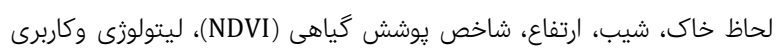
اراضى بررسى شد.

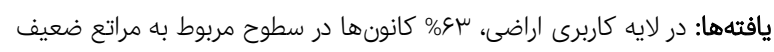

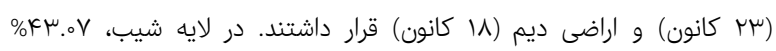

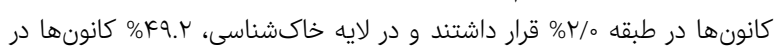

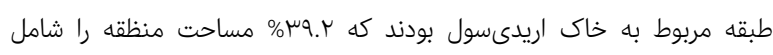

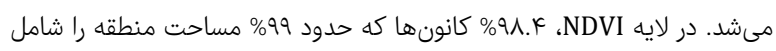
مىشد، مربوط به قسمت بدون يوشش گياهى بود و در لايه مرايه مربوط به نقاط

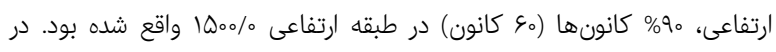

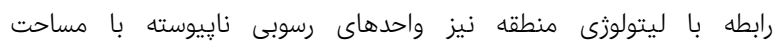

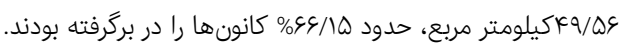

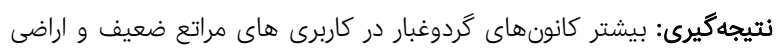

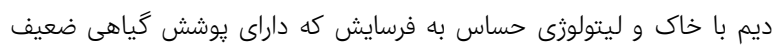
است قرار دارد. كليدوازمها: كانونهاى گرد و غبار، مناطق خشك، يوشش گياهى، خراسان رضوى

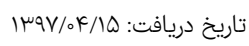

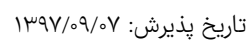
"نويسنده مسئول: تاريخ بذشر: amirahmadi1388@gmail.com

مقدمه

طوفان كَدوغبار باطور طبيعى در مناطق خشك و نيمانش

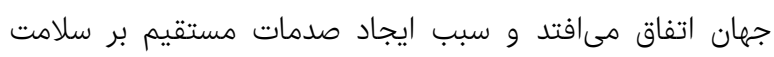

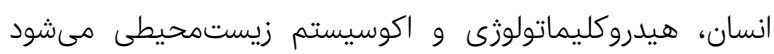

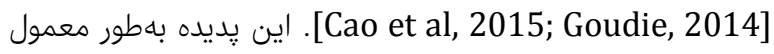

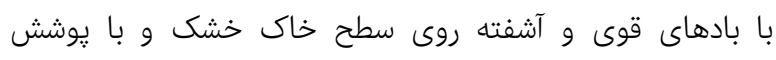

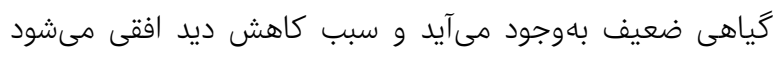
[Zoljoodi et al, 2013] 


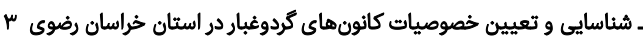

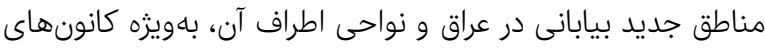

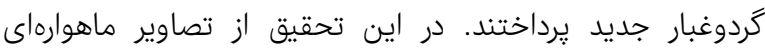
MODIS

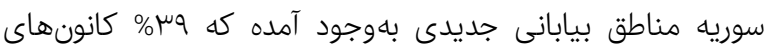

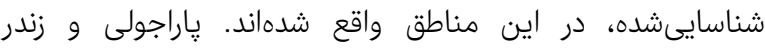

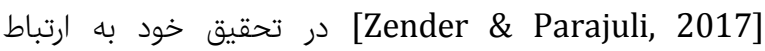
زئومورفولوزى با انتشار گردوغبار با استفاده از نقشههاى فرسايش

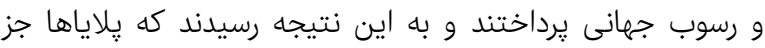

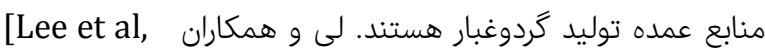

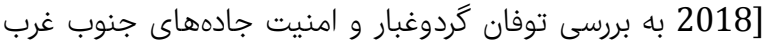

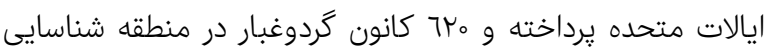

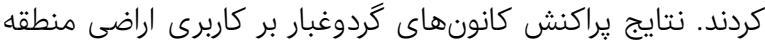

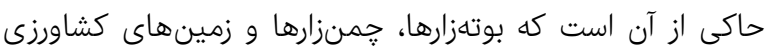

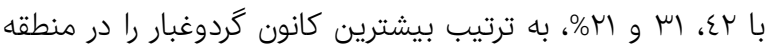

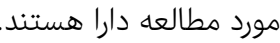
با توجه به اهميت توفانهاى گردوغبار در ايران و منطقه خراسان رضوى و همجنين لزوم شناخت و كنترل اين بديده، هدف إن از اين تحقيق، شناسايى و بررسى خصوصيات كانونهاى گَردوغبار در استان خراسان رضوى بود.

\section{روش رشناسى}

منطقه مورد مطالعه

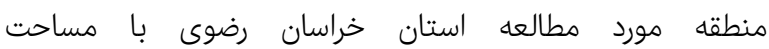


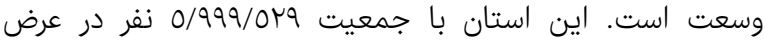
جغرافيايى 'or or خُ707 $07^{\circ}$

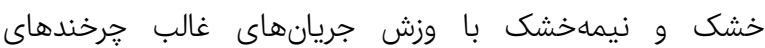

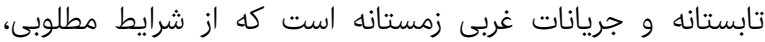

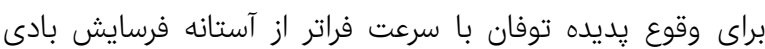

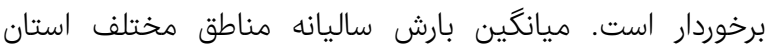

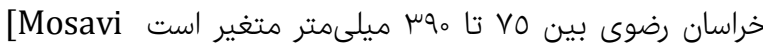

.Bayghi \& Ashraf, 2011]

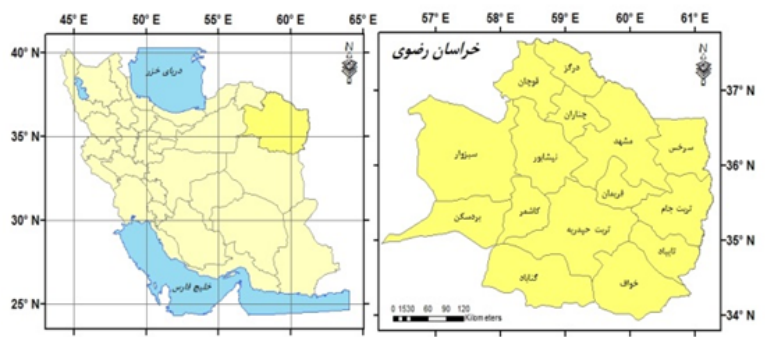

شكل () نقشه استان خراسان رضوى (- مي

شناسايى كانونهاى گردوغبار

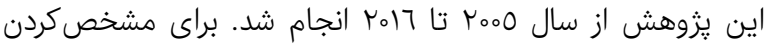

در جنوب غربى آمريكاى شمالى يرداختند. در اين تحقيق از

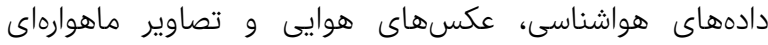
استفاده شد. 7 اع كانون برداشت كَردوغبار در منطقه مورد

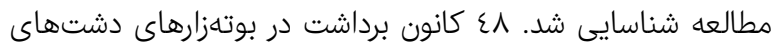

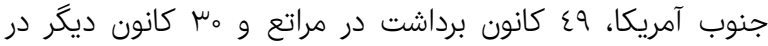

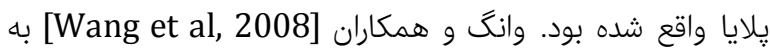

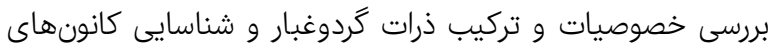

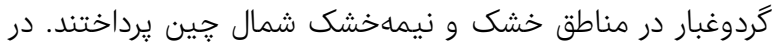

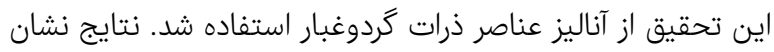

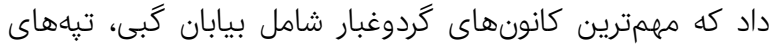

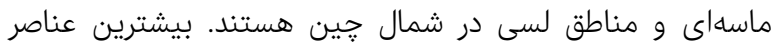

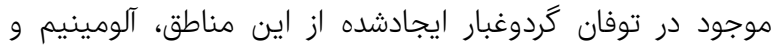

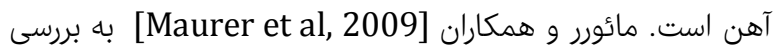

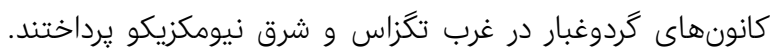

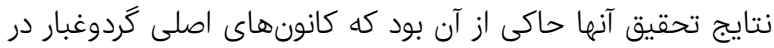

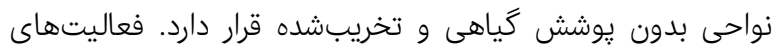
انسانى كه باعث تخريب زمين در آن منطقه شده است، كاند كانونهاى

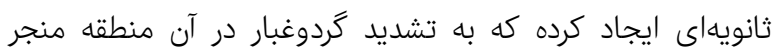
شده است. لى و همكاران [Lee et al, 2012] با استفاده از كناز سنجش از دور به بررسى خصوصيات زئومورفيكى و يوشش سطح

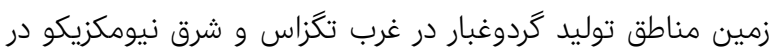

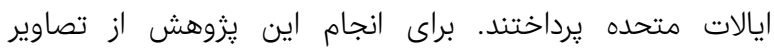

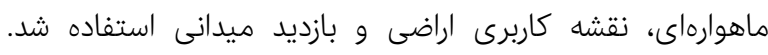

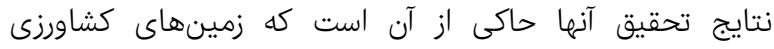

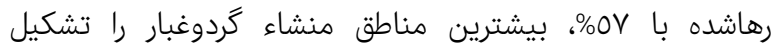
مى مهند. راشكى و همكاران [Rashki et al, 2013] با استفاده از تصاوير ماهوارهاى سنجنده MODIS به بران درياجههاى موقتى و متعاقب آن فعاليت كردوغبار در منطقه حوزه

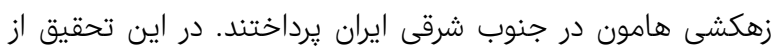

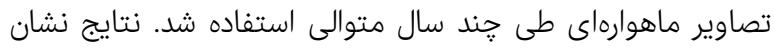

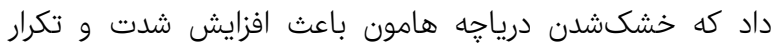

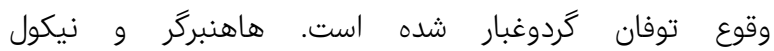
[Hahnenberger \& Nicoll, 2014] با استفاده از فن سنجش تونش از دور به ريختشناسى و يوشش سطحى زمين مناطق منشاء

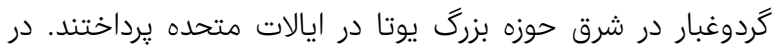

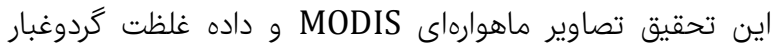

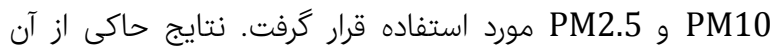

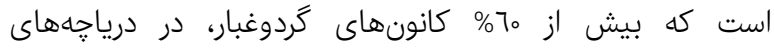
خشكشده و بدون يوشش سطحى با خاك سيلتى رسى قرار قرار دارد. كائو و همكاران [Cao et al, 2015] در تحقيقى به شناسايى كانونهاى كردوغبار در غرب آسيا با استفاده از دادههاى محيطى دران

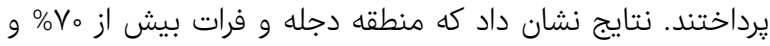

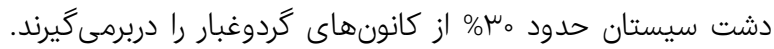

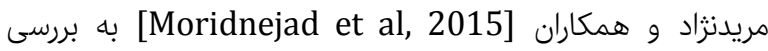


معادلهى يلانك، يارامتر درجه حرارت را مىتوان با رابطه (r)

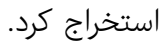

$T=\frac{h c}{\lambda k \ln \left(1+\frac{2 h c^{2}}{L \lambda^{5}}\right)}$

رابطه (r)

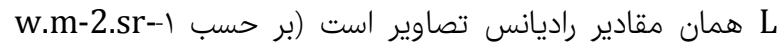

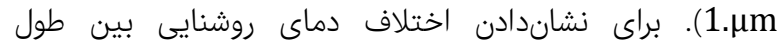

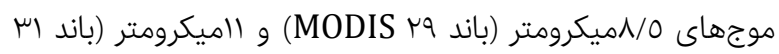
MODIS

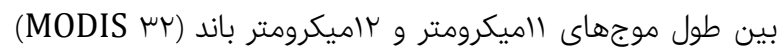

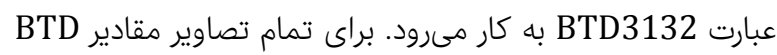

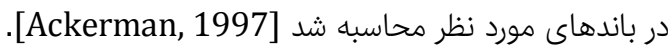
شاخص NDDI براى رديابى توفان كَدوغبار با استفاده از رابطه سـ

محاسبه شد.

رابطه (س)

p.13 و $p_{2.13}$

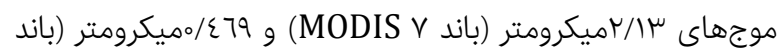

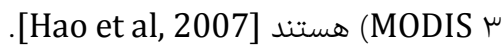
شاخص D ويزگگهاى بازتابندگى و نيز اختلاف دماى درخشندگى إنى

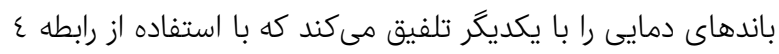
محاسبه شد. $D=\exp \{-[r r \times a+(b t d-b)]\} \quad$ (ع)

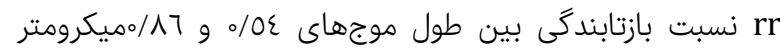

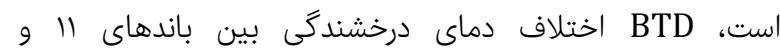
rاميكرومتر و a و ض طرايب ثابتى هستند كه توسط كاليبره كردن

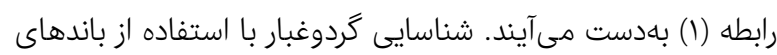

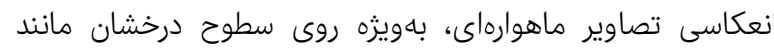

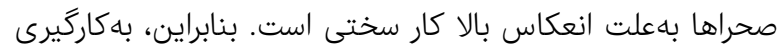

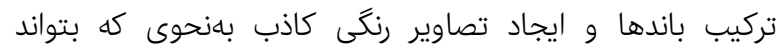

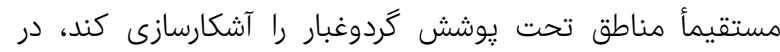

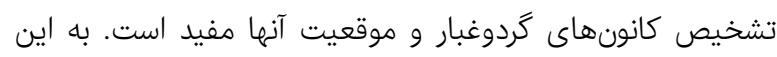
منظور شاخصهاى تشخيص مناطق كَردوغبار ايجاد و مقان مقدار

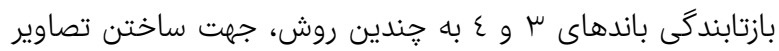

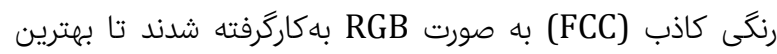
تصويرى كه مىتواند كانونهاى كردوغبار را آشكارسازى نمايد،

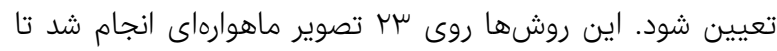
كانونهاى گردوغبار در منطقه مورد مطالعه مشخص شودي

بررسى خصوصيات كانونهاى گردوغنبار

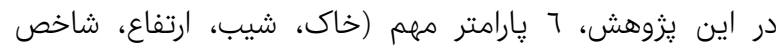

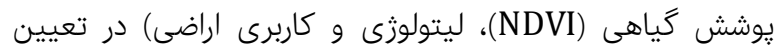

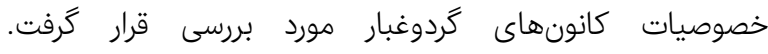

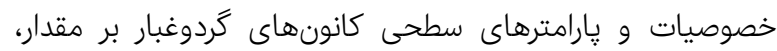

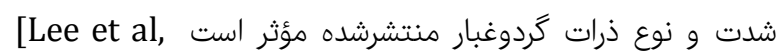

تعداد روزهاى همراه با كردوغبار در منطقه مورد مطالعه، ابتدا براى

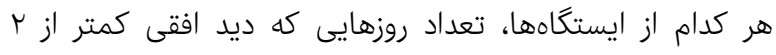

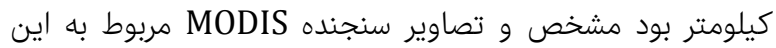

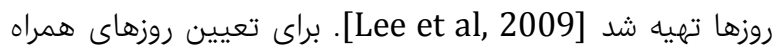

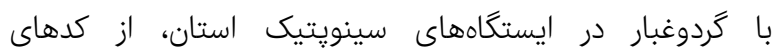

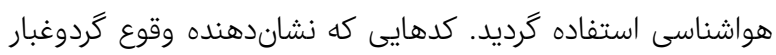

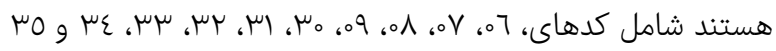

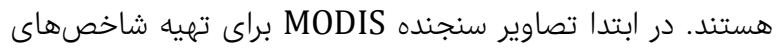

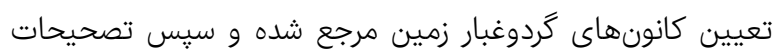

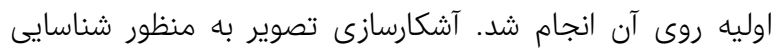

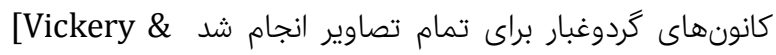

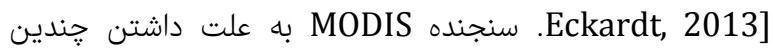

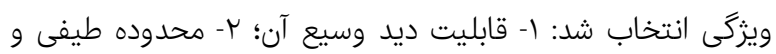

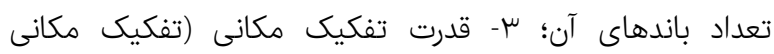

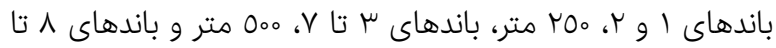

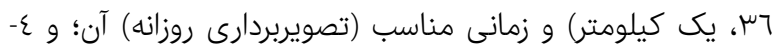
دردسترسبودن دادههاى اين سنجنده در ايران Hahnenberger] \& Kathleen, 2014; Walker et al, 2009; .Engelstaedter et al, 2003] ڤارامترهاى ارايهشه براى رديابى كانونهاى گردوغبار BTD3132،

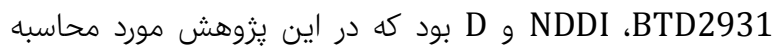

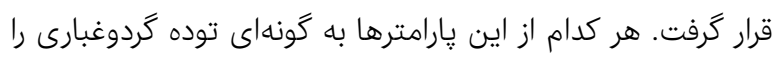

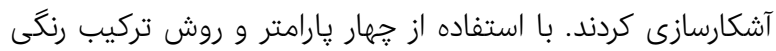

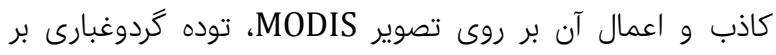

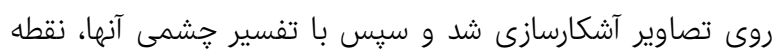

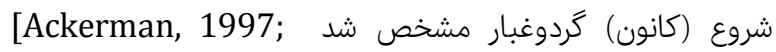

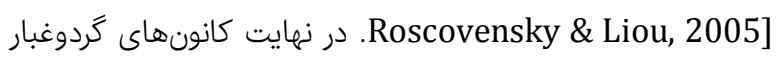
در منطقه مورد مطالعه شناسايى شد. قاعده تشخيص كانونهاى

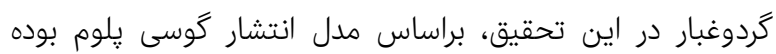

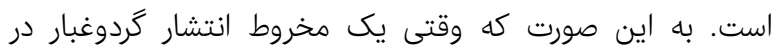

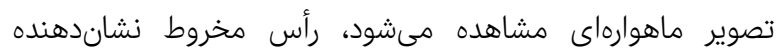

$$
\text { كانون كَدوغبار است. }
$$

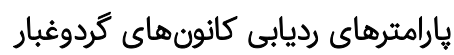

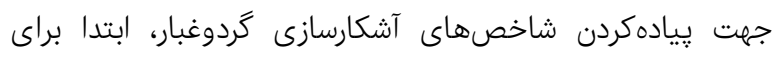

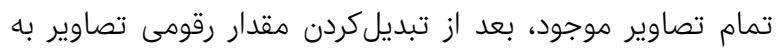

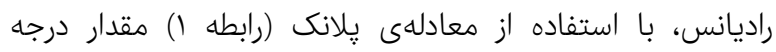
حرارت روشنايى باندهاى || ، N/0 و باميكرومتر تصاوير محاسبه

$B(T, \lambda)=\frac{2 h c^{2}}{\lambda^{5} \frac{h c}{(e \lambda k T-1)}}$

تابع يلانك در يك طول موج (T) مشخص (T)،

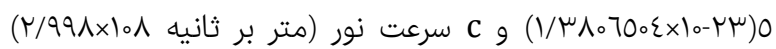

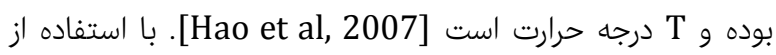




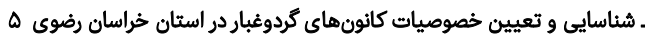

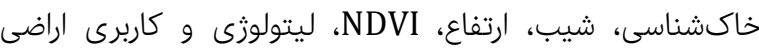

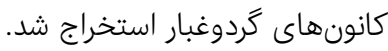

يافتهها

در مجموع 70 كانون گردوغبار در كل منطقه شناسايى شد (جدول

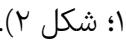

جدول () درصد يراكنش كانونهاى گردوغبار در طبقات كاربرى اراضى

\begin{tabular}{|c|c|c|c|c|}
\hline گردوغبار & كردوغبار & مساحت & (كيلومترمربع) & كاربرى اراضى \\
\hline rV/दqr & 11 & $|\varepsilon / 9| \mathrm{K}$ & $19 k 94 / 901$ & اراضى ديم \\
\hline V/DHA & 1 & $\circ / T Y K$ & $\mu r r / F \mid$ 。 & جنكالهاى طبيعى \\
\hline$K / 91 Q$ & $\mu$ & $\Delta / \mu q_{0}$ & GMYK/IKK & جنكلهاى مصنوعى \\
\hline IH/Aks & 9 & I I & $|\varepsilon r \mu \mu / ৭ \&|$ & اراضى كشاورزى آبى \\
\hline 。 & $\circ$ & $\%$ & $10 / Y_{0} 9$ & سطوح آبى \\
\hline V/QH & 1 & $r / V V \mu$ & KTQH/AIr & مراتع غنى \\
\hline$\mu \Delta / \Psi \wedge F$ & r & IN/V०H & $\mu / 9 k \mu / \mu \wedge \Delta$ & مراتع ضعيف \\
\hline$q / \Upsilon \mu$ 。 & 4 & rV/arA & 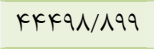 & مراتع متوسط \\
\hline r/॰Vद & r & $1 / \mu V V$ & $1919 / 001$ & سطوح رسى(دق) \\
\hline$\mu / \circ \vee \varphi$ & r & $r / \mu \Delta S$ & TVGF/VAT & سطوح نمكى \\
\hline 。 & 。 & $o / A V Y$ & $\Delta Q K / G_{0} K$ & مناطق مسكونى \\
\hline 。 & 。 & $\circ / T \Delta \Lambda$ & $\mu \circ \mu / \mu \wedge \mu$ & بسترهاى سيلابى \\
\hline
\end{tabular}

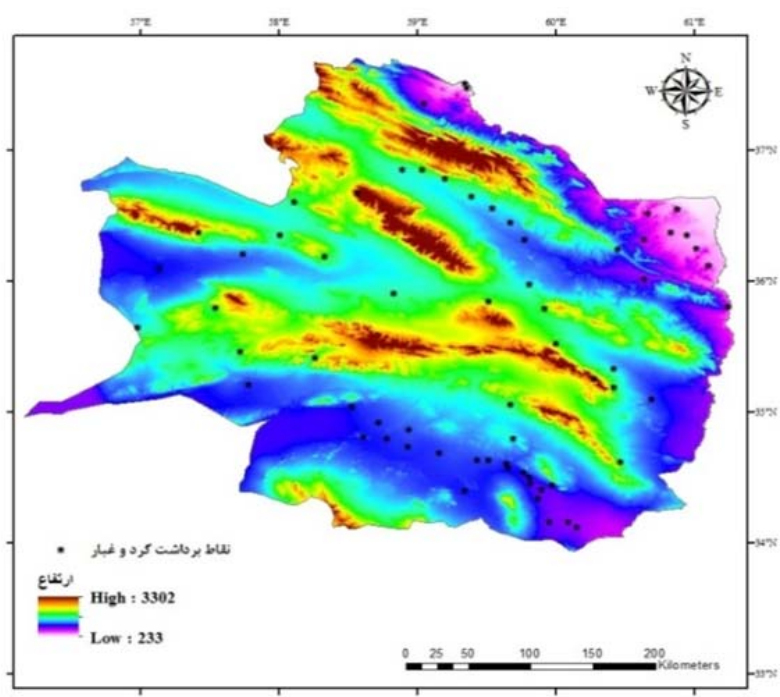

شكل r) نقشه يراكنش كانونهاى گردوغبار در خراسان رضوى

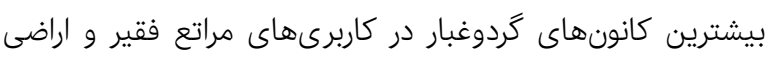

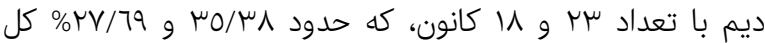
كانونهاى منطقه مورد مطالعه را شامل مى دانود، قرار داش داشت (شكل

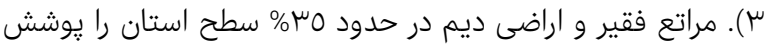

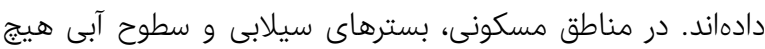

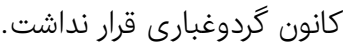

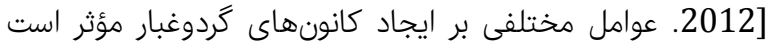

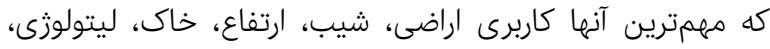

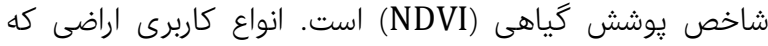

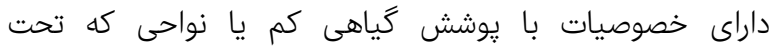

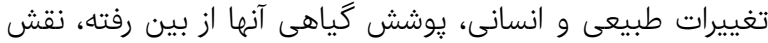
بيشترى در برداشت ذرات خاك و ايجاد كانون گردودغبار دارند

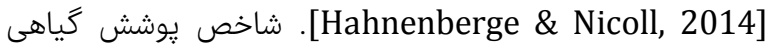
الخوى گَستردهاى از تغييرات يوشش گياهى را نشان

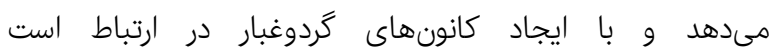

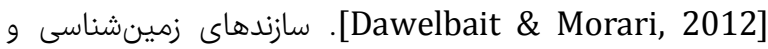
خاكهاى حساس به فرسايش نقش زيادى در ايجاد كانونهاى

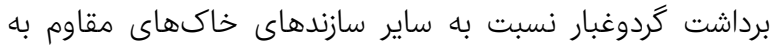

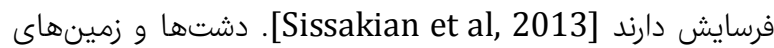
مسطح و با شيب و ارتفاع كم نسبت به شيبهاى زياد، دارئ دارى

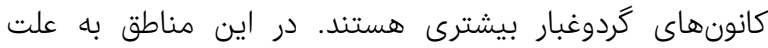

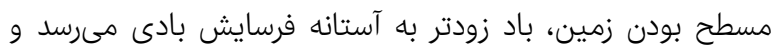

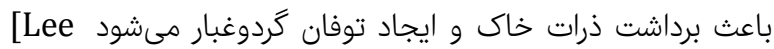
.et al, 2009] لايه مربوط به مدل رقومى ارتفاع (DEM) براى استان خراسان

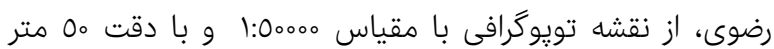

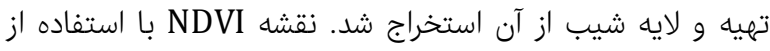

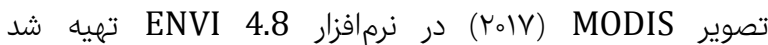

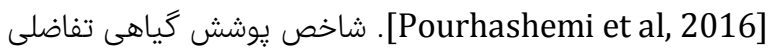

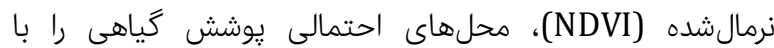

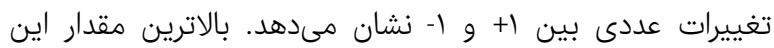
شاخص (ا+) است كه نشاندهنده بيشترين ميزان تراكم يوشش بانش

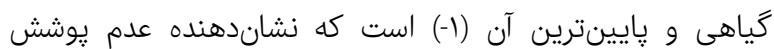

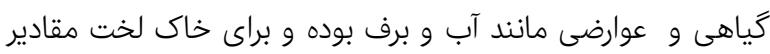

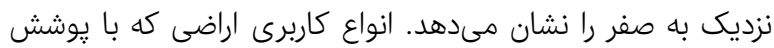

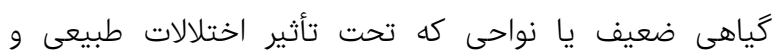

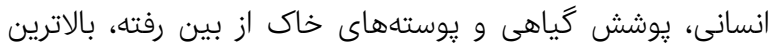

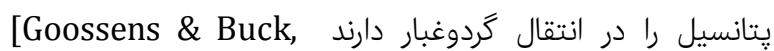
[2009. نقشه كاربرى اراضى با استفاده از تصاوير ماهوارهاى

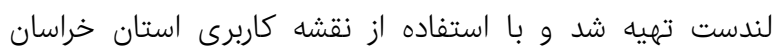

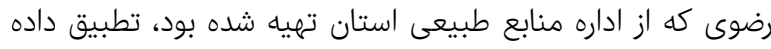

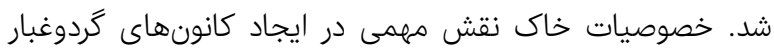
دارد. نقشه خاكشناسى استان خراسان رضوى از نقان نقشه خان خاك جهانى استخراج و نقشه ليتولوزى منطقه مورد مطالعه در مقياس

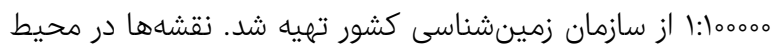
GIS رقومى و لايههاى سنكگشناسى از آن استخراج شد.

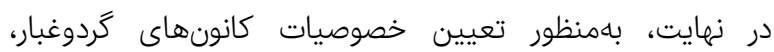
همبوشانى نقشه كانونهاى گردوغبار با نقشههاى خاك، شيب،

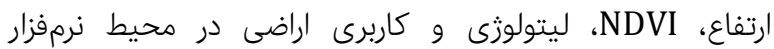
ArcGIS 
\%0\% كل كانونهاى منطقه را شامل شد)، قرار داشت (شكل 0).

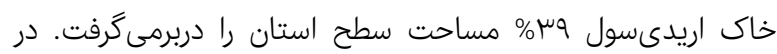

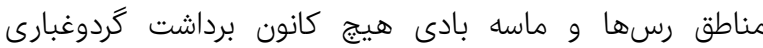
مشاهده نشده است (جدول سم).

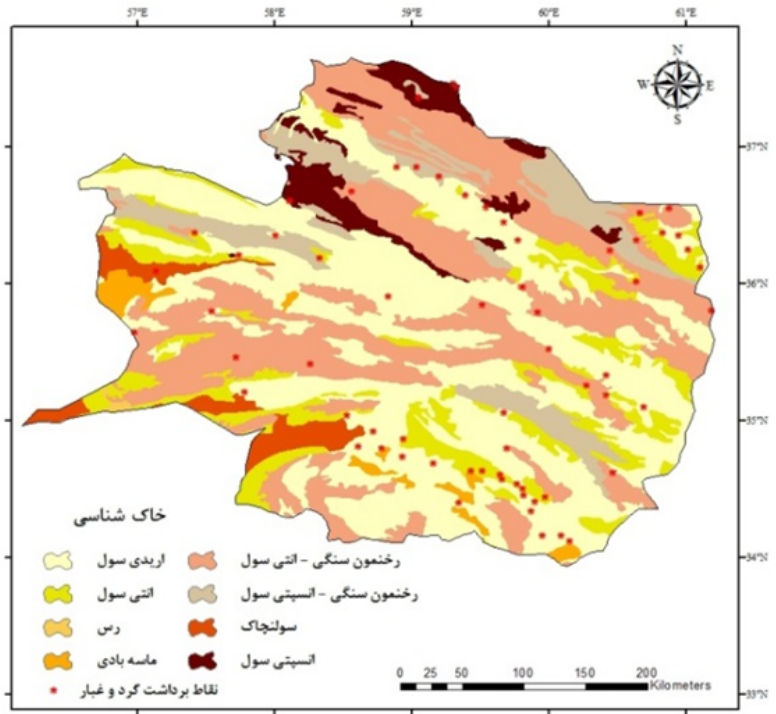

شكل Q) نقشه يراكنش كانونهاى گردوغبار در طبقات مختلف خاكشناسى

جدول س) درصد يراكنش كانونهاى گردوغبار در طبقات خاكشناسى

\begin{tabular}{|c|c|c|c|c|}
\hline كردوغبار & كردوغبار & مساحت & (كيلومترمربع) & 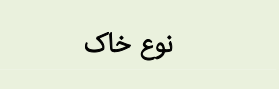 \\
\hline$k q / \mu \mu_{0}$ & $\mu r$ & $r q / r q q$ & $\kappa \varepsilon \circ \Delta \xi / \wedge q \Delta$ & اريدىسول \\
\hline $1 Q / \mu \lambda k$ & 10 & IT/Ook & $\mid K_{0} V_{0} / I r r$ & انتىسول \\
\hline 。 & 。 & ./Ar & IKF/VKG & رسها \\
\hline 。 & 。 & I/VM & 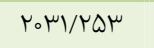 & ماسه بادى \\
\hline ro & w & $\mu_{0}$ & 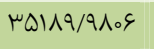 & رخنمون سنگى-انتىسول \\
\hline V/צ१Y & $\Delta$ & $q / 1 \mu r$ & loV.K/०Vq & رخنمون سنگى- انسيتىسول \\
\hline $1 / \Delta \mu \wedge$ & 1 & H/MQI & rgqF/ $\mu_{0} \wedge$ & سولنجاك (خاك شور) \\
\hline S/DQH & k & K/FYN & $\Delta 1 q_{0} / \varepsilon \Delta K$ & انسيتىسول \\
\hline
\end{tabular}

بيشترين كانونهاى كُدوغبار با تعداد اس كانون (^乞\%) در ارتفاع

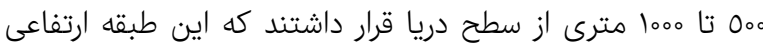

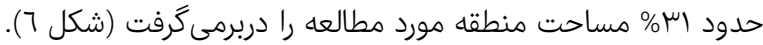

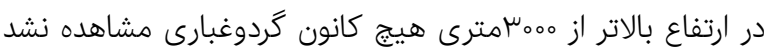

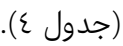

جدول F) درصد يراكنش كانونهاى گردوغبار در طبقات ارتفاعى

\begin{tabular}{|c|c|c|c|c|}
\hline كردوغبار & كردوغبار & مساحت & (كيلومترمربع) & ارتفاع (متر) \\
\hline $10 / V \& 9$ & $\mathrm{v}$ & $r / T Q Q$ & $r \in \Delta Q / \circ \mid \mathcal{A}$ & $0-\omega_{\circ \circ}$ \\
\hline FV/\&QY & ו & سו/rqщ & mGVVr/rqA & Q00-1000 \\
\hline нस/Aks & $r \mu$ & KY/MAG & 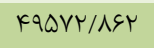 & $1000-10000$ \\
\hline$k / 910$ & $\mu$ & $\mid N / \mu^{\mu} \gamma^{\mu}$ & $M \mid \Delta q_{0} / \Lambda_{\circ} \Lambda$ & 1Q0o-Y Yoo० \\
\hline 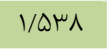 & 1 & $Q / \circ \mu q$ & Q9YI/N०D & Yoo- YQ.०० \\
\hline I/DHA & 1 & o/AYK & $9 \& / / \wedge \mid \Delta$ & $r \omega_{00-} \mu_{\circ o 0}$ \\
\hline 。 & 。 & $\%$ \% & YN/DVq & $>\mu_{000}$ \\
\hline
\end{tabular}

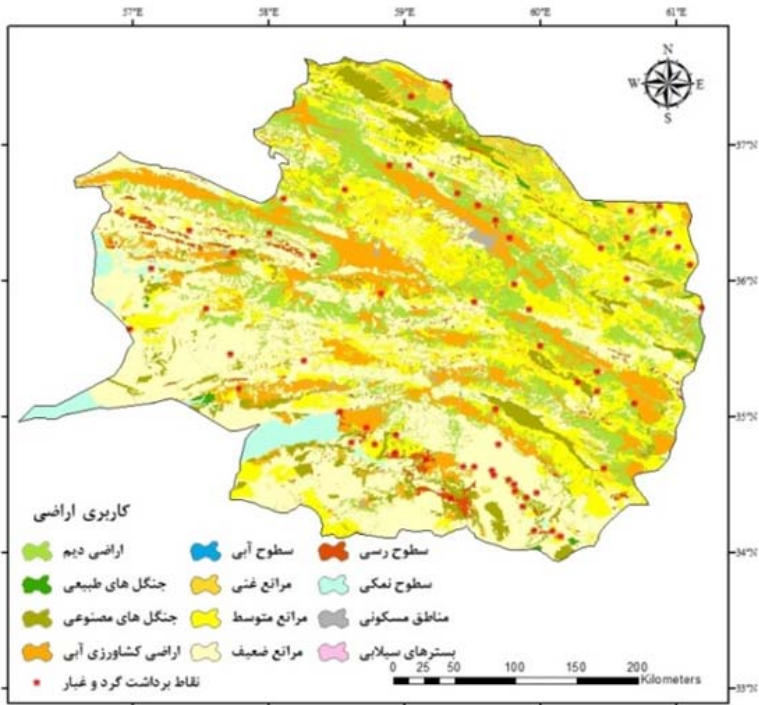

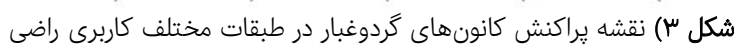

بيشتر كانونهاى گردوغبار در بخشهاى كمشيب استان قرار

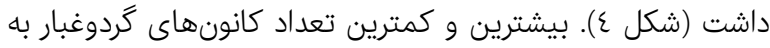

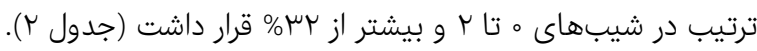

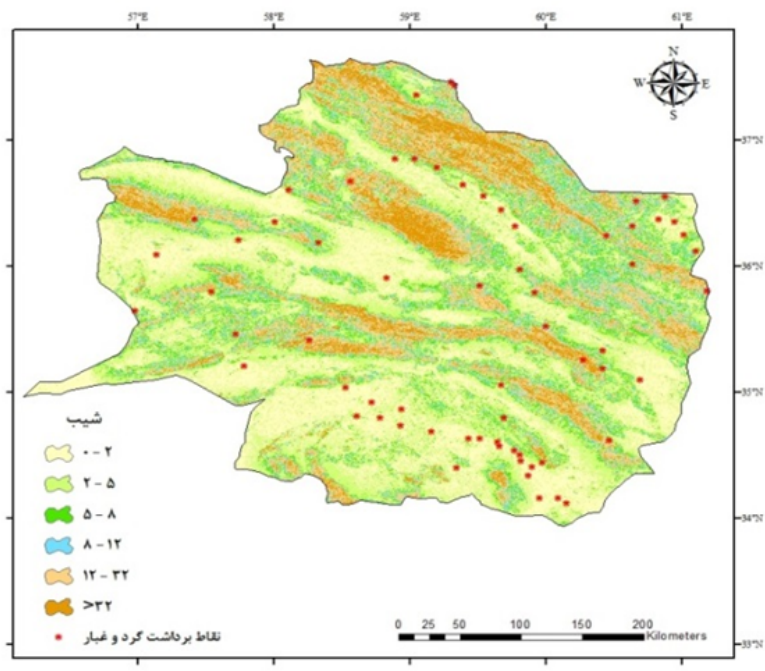

شكل F) نقشه يراكنش كانون هاى گَردوغبار در طبقات مختلف شيب

\begin{tabular}{|c|c|c|c|c|}
\hline گردوغبار & كردوغبار & مساحت درصد & مساحت (كيلومترمربع) & شيب \\
\hline $\mathrm{k \mu} / \circ \mathrm{\vee}$ & ru & $r / \Lambda 9 \Delta$ & 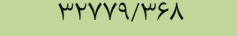 & $0-r$ \\
\hline$r V / \& q Y$ & 11 & $r V / V \mu r$ & $\mu r \Delta \wedge V / \kappa \mu \Lambda$ & $r-\omega$ \\
\hline $\mid r / \mu \circ V$ & $\wedge$ & $10 / 490$ & $\mid r \mu \mu \mu / \Delta s 9$ & $\Delta-\Lambda$ \\
\hline s/NQH & k & $\Lambda / \mu$ & $9 \vee \Delta S / K \Delta U$ & $A-M$ \\
\hline$q / \mu \mu_{0}$ & 4 & $\mid N / T \circ D$ & 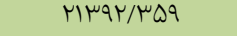 & $\mid r-\mu r$ \\
\hline $1 / \Delta \mu \wedge$ & 1 & $V / W^{L} \sigma_{0}$ & $\Lambda \varepsilon k q / \varepsilon \mu \mu$ & $>\mu r$ \\
\hline
\end{tabular}

بيشترين كانونهاى گردوغبار در خاكهاى اريدىسول (كه خاى مناطق خشك و بيابانى هستند) با بس كانون برداشت (كه تقرئار 


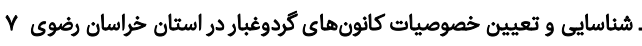

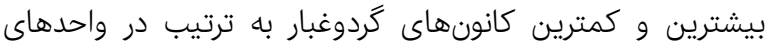

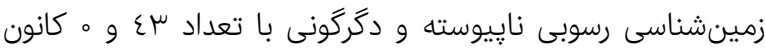

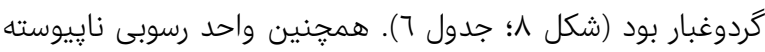

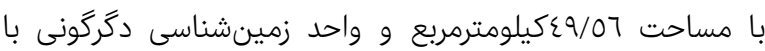
مساحت سرح/\%/ از سطح استان، به ترتيب بيشترين و كمترين

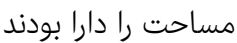

جدول \&) درصد يراكنش كانونهاى گردوغبار در گروههاى ليتولوزى

\begin{tabular}{|c|c|c|c|c|}
\hline گردوغبار & كردوغبار & مساحت & (كيلومترمربع) & ليتولوزى \\
\hline$r \varepsilon / \Lambda Q \mu$ & IV & rN/צQR & $K \Delta H K Q / T Q V$ & رسوبى بيوسته \\
\hline$\varepsilon \varphi / \triangle Q \mu$ & $k \mu$ & $K Q / \Delta \& K$ & $\Delta \wedge \mid k V / q 1 \Lambda$ & رسوبى ناييوسته \\
\hline S/NQH & $k$ & १/マ८৭ & llkAk/VqV & آتشفشانى \\
\hline $1 / \Delta \mu \Lambda$ & 1 & $1 / \mu / 。$ & $\mid Q \Psi V / T S V$ & نفوذى \\
\hline 。 & 。 & 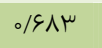 & $\Lambda_{0} 1 / \mu \vee \Delta$ & دگرگونى \\
\hline
\end{tabular}

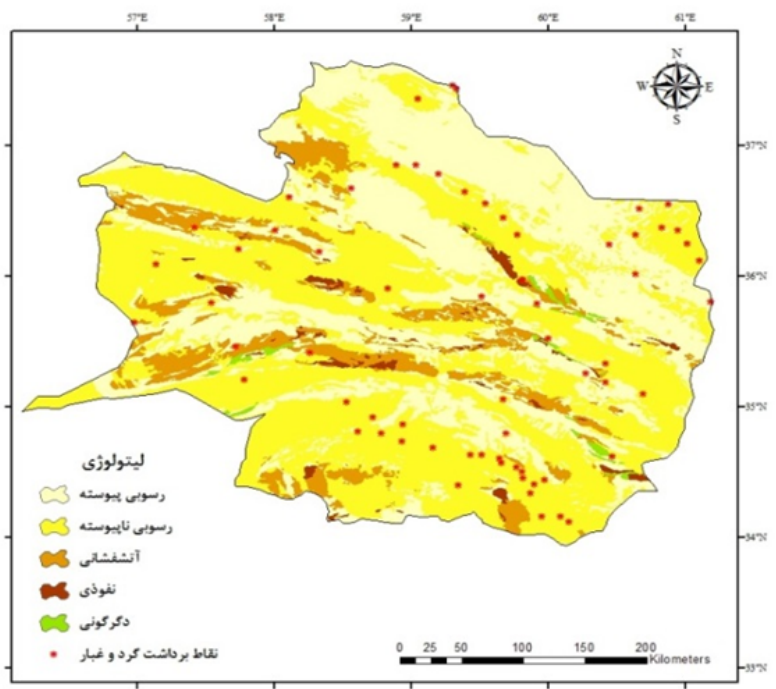

شكل ^) پراكنش كانونهاى گردوغبار روى نقشه ليتولوزى منطقه مورد مطالعه

بحث

در اين تحقيق به شناسايى كانونهاى گردوغبار با استفاده از

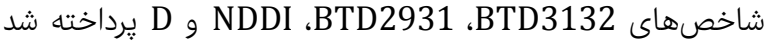
و در نهايت 7 يارامتر مهم خاك، شيب، ارتفاع، شاخص يوشش

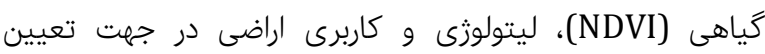
خصوصيات كانونهاى گردوغبار مورد استفاده قرار گرفت. 70 كانون برداشت گردوغبار در منطقه مورد مطالعه شناسايى شد كه كه

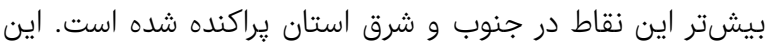

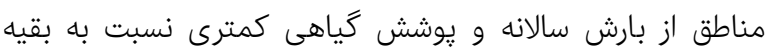

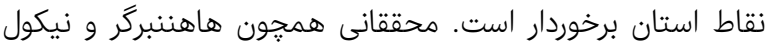

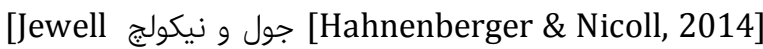
[Miller et al, ميلر و همكاران \& Nicoll et al, 2012] [2012، لى و همكاران [Lee et al, 2009]، كرووى و همكاران [Zobeck et al, و زوبك و همكاران [Crouvi et al, 2012] [2013 به بررسى خصوصيات كانونهاى گردوغبار و تعيين زون

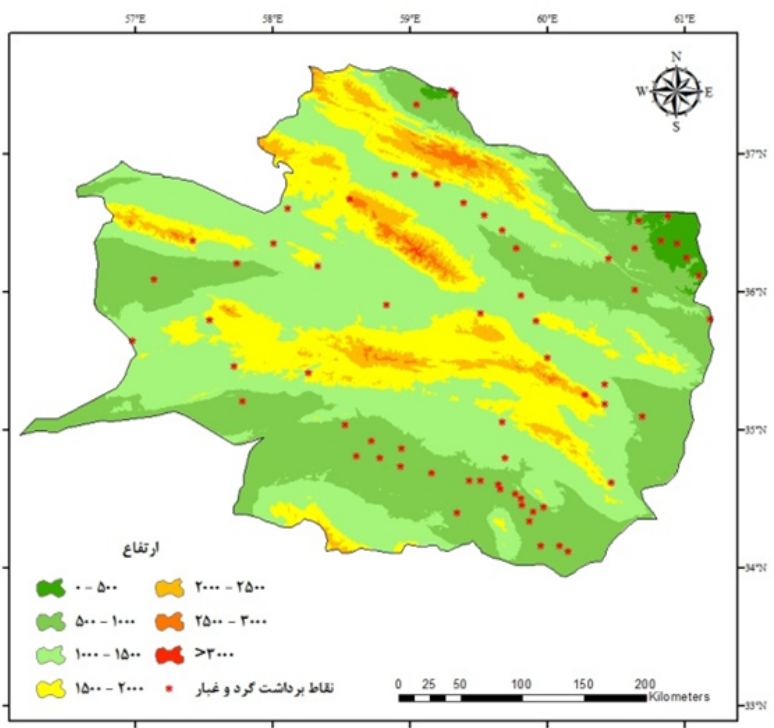

شكل \&) نقشه يراكنش كانونهاى كَردوغبار در طبقات مختلف ارتفاعى

تمام كانونهاى گردوغبار در طبقه 9.ع/ه- تا ץه/ قرار داشت كه

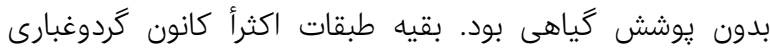
نداشت (شكل \؛ جدول 0).

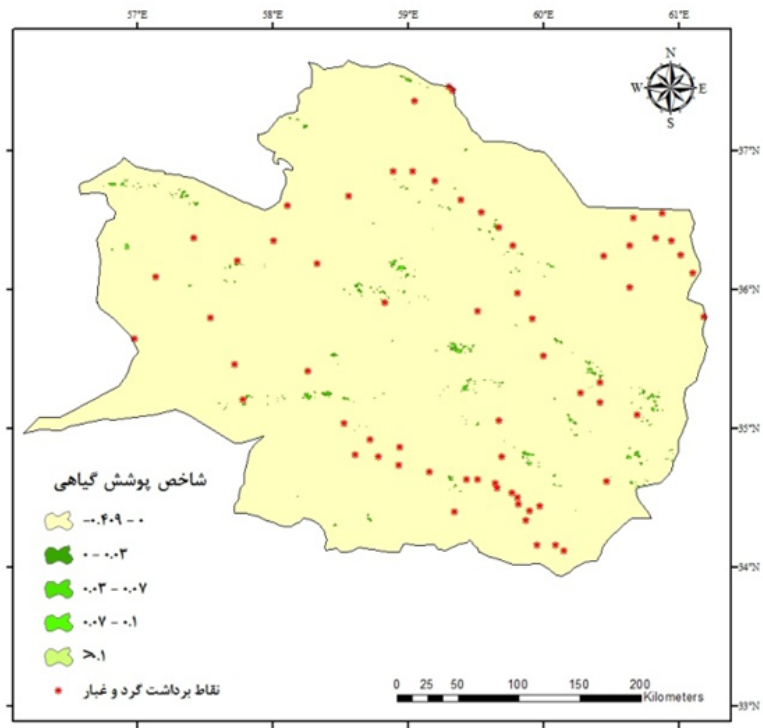

شكل V) يراكنش كانونهاى گَردوغبار در طبقات مختلف شاخص يوشش گَاهى

\begin{tabular}{|c|c|c|c|c|}
\hline گردوغبار & گردوغبار & مساحت درصد & (كيلومترمربع) & شاخص يوششى \\
\hline $9 / / 4<1$ & sk & $৭ 9 / 4 \& \wedge$ & $\| \xi q \vee k / \mu \wedge q$ & $-0 / \mathbb{F}_{\circ} q_{-0}$ \\
\hline $1 / \Delta \mu \Lambda$ & 1 & ( & KrY/Krq & o-o\% \\
\hline 。 & 。 & هس & $|Q Q / T|_{0}$ & $\circ / \odot \mu-\circ / \circ V$ \\
\hline 。 & 。 & $\% Y \Delta$ & $r q / q \Lambda k$ & $0 \% \vee-0 / 01$ \\
\hline 。 & 。 & 1009 & $\wedge$ & $>0 \% 1$ \\
\hline
\end{tabular}

ليتولوزى متغير مهمى در تجزيه و تحليل مخاطرات محيطى است

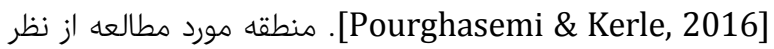
ساختار زمينشناسى به 0 واحد (رسوبى يِيوسته، رسوبى ناييوسته،

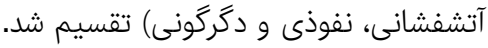




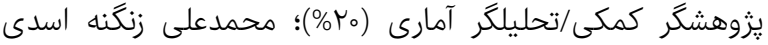

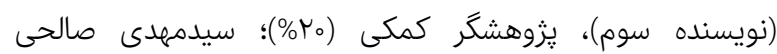

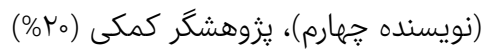

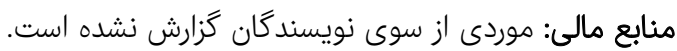

- Ackerman SA (1997). Remote sensing aerosols using satellite infrared observations. Geophysical Research. 102(D14):17069-17080.

- Baddock MC, Gill TE, Bullard JE, Dominguez Acosta M, Rivera NI (2011). Geomorphology of the chihuahuan desert based on potential dust emissions. Maps. 7(1):249-259.

- Boroghani M, Pourhashemi S, Zanganeh Asadi MA, Moradi HR (2017). Dust Source Identification in the Middle East by Using Remote Sensing. Natural Environmental Hazards. 6(11):101-118. [Persian]

- Bullard J, Baddock M, McTainsh G, Leys J (2008). Subbasin scale dust source geomorphology detected using MODIS. Geophysical Research Letters. 35(15):1-19.

- Cao H, Amiraslani F, Liu J, Zhou N (2015). Identification of dust storm source areas in West Asia using multiple environmental datasets. Science of the Total Environment. 502:224-235.

- Crouvi O, Schepanski K, Amit R, Gillespie AR, Enzel Y (2012). Multiple dust sources in the Sahara Desert: the importance of sand dunes. Geophysical Research Letters. 39:L13401.

- Dawelbait M, Morari F (2012). Monitoring desertification in a Savannah region in Sudan using Landsat images and spectral mixture analysis. Journal of Arid Environments. 80:45-55.

- Ebrahimi Khosfi Z, Vali AA, Khosroshahi M, Ghazavi R (2017). Investigation of the role of bed dried Gavkhooni wetland on the production of the internal dust using remote sensing and duststorms (Case study: Isfahan province). Rangeland and Desert Research. 24(1):152164. [Persian]

- Engelstaedter S, Kohfeld KE, Tegen I, Harrison SP (2003). Controls of dust emissions by vegetation and topographic depressions: an evaluation using dust storm frequency data. Geophysics Research Letter. 30(6).27-31. - Floyd KW, Gill TE (2011). The association of land covers with aeolian sediment production at Jornada Basin, New Mexico, USA. Aeolian Research. 3(1):55-66.

- Goossens D, Buck B (2009). Dust dynamics in off-road vehicle trails: measurements on 16 arid soil types, Nevada, USA. Environmental Economics and Management. 90(11):3458-3469.

- Goudie A (2014). Review Desert dust and human health disorders. Environment International. 63(3):101-113.

- Hahnenberger M, Nicoll K (2014). Geomorphic and land cover identification of dust sources in the eastern Great Basin of Utah, U.S.A. Geomorphology. 204(2):657-672.

- Hao X, Qu J, Hauss B, Wang C (2007). A highperformance approach for brightness temperature inversion. International Journal of Remote Sensing. 28(21):4733-4743.

- Jewell PW, Nicoll K (2011). Wind regimes and aeolian transport in the Great Basin, U.S.A. Geomorphology. 129(1-2):1-13.

- Karimi K, Shahraeni H, NowKhandan M, Hafezi Moghadas N (2011). Dust source identification in Middle

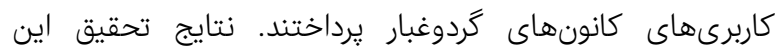

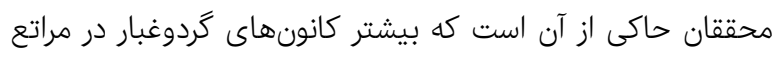

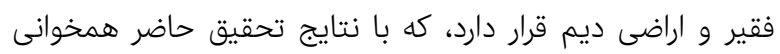

دارند.

محققانى همجون ليندلى و همكاران [lindley et al, 2011]،

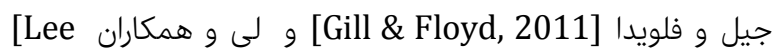
شرايط آب و هوايى خشك و نيمهخشك، يوشش ياهى ضعيف و رسوبات سختنشده را از عوامل مؤثر در

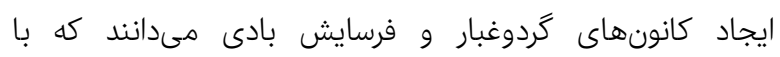
ويزگى هاى منطقه مورد مطالعه همخوانى دارد. اين نتايج با نتايج

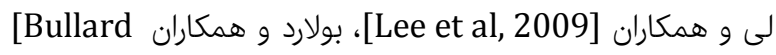
[Jewell \& Nicoll et al, 2012] جول و نيكول [Je1, 2011] سانكى و همكاران [Sankey et al, 2013] و هاهننبركر و نيكول

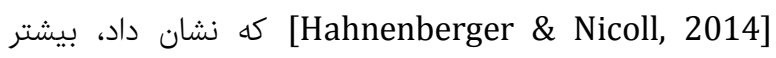
كانونهاى گردوغبار در خاكهاى حساس به فرسايش قرار دارد،

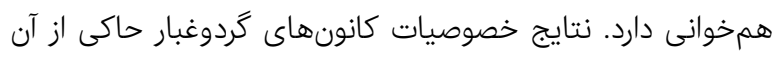

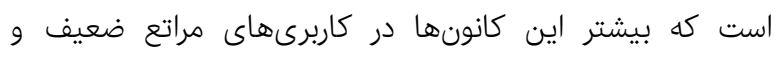
زمينهاى ديم با خاك حساس به فرسايش كه داراى يوشش

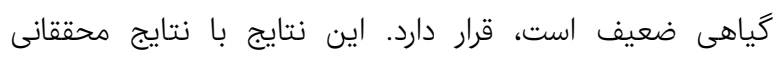

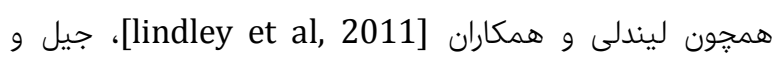
فلويد [Gill \& Floyd, 2011] و ريورا ريورا و همكاران 2011) كه يوشش گياهى ضعيف و رسوبات سخت نشده را از عوامل مؤثر در ايجاد كانونهاى كردوغبار و و فرسايش بادى مىدانند، همخوانى دارد.

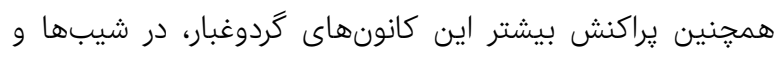

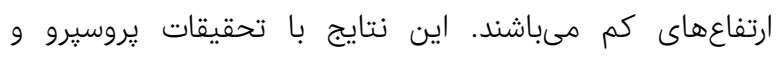

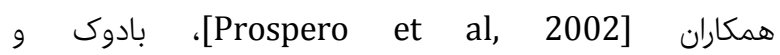
همكاران [Baddock et al, 2011]، هولارد و همكاران Bullard] [Moridnejad et al, و مريدنزاد و همكاران et al, 2011] [2015 كه به بررسى خصوصيات كانونهاى گردوغبار در نقاط مختلف جهان يرداخته و به اين نتيجه رسيدهاند كه بيشتر بران

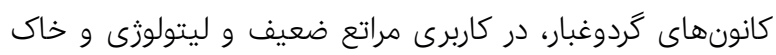
حساس به فرسايش قرار دارند، همخوانى دارد.

\section{نتيجه گيرى}

بيشتر كانونهاى گردوغبار در استان خراسان رضوى در كاربرىهاى

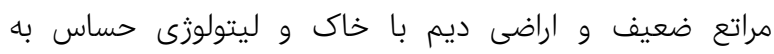
فرسايش كه داراى يوشش گياهى ضعيف است قرار دارد.

$$
\begin{aligned}
& \text { تشكر و قدردانى: موردى از سوى نويسندگان گزارش نشده است. }
\end{aligned}
$$

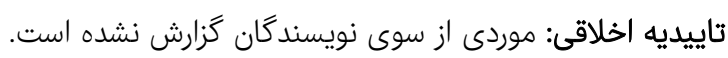

$$
\begin{aligned}
& \text { تعارض منافع: موردى از سوى نويسندكان كزارش نشده استان. }
\end{aligned}
$$

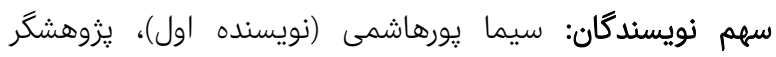

$$
\begin{aligned}
& \text { اصلى/نكارنده بحث (هع\%)؛ ابوالقاسم اميراحمدى (نويسنده دورئ دوم)، }
\end{aligned}
$$




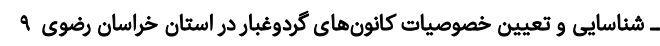

Dryness of ephemeral lakes and consequences for dust activity: The case of the Hamoun drainage basin, southeastern Iran. Science of the Total Environment. 463-464(3):552-564.

- Rashki A, Kaskaoutis DG, Rautenbach C, Eriksson PG, Qiang M, Gupta P (2012). Dust storms and their horizontal dust loading in the Sistan region, Iran. Aeolian Research. 5(3):51-62.

- Rezazadeh M, Irannejad P, Shao Y (2013). Climatology of the Middle East dust events. Aeolian Research. 10:103109.

Rivera Rivera NI, Gill TE, Bleiweiss MP, Hand JL (2010). Source characteristics of hazardous Chihuahuan Desert dust outbreaks. Atmospheric Environmental. 44(20):2457-2468.

- Roscovensky JK, Liou, KN (2005). Differentiating airborne dust from cirrus clouds using MODIS data. Geophysical Research Letters. 32(12):L12809.

- Sankey JB, Wallace CSA, Ravi S (2013). Phenologybased, remote sensing of post-burn disturbance windows in rangelands. Ecological Indicators. 30:35-44.

- Sissakian V, Al-Ansari N, Knutsson S (2013). Sand and dust storm events in Iraq. Natural Science. 5(10):10841094.

- Sweeney MR, McDonald EV, Etyemezian V (2011). Quantifying dust emissions from desert landforms, eastern Mojave Desert, USA. Geomorphology. 135: 2134.

- Tan M, Li X, Xin L (2014). Intensity of dust storms in China from 1980 to 2007: A new definition. Atmospheric Environment. 85(4):215-222.

- Tsolmon R, Ochirkhuyag L., Sternberg T (2008). Monitoring the source of trans-national dust storms in north East Asia. International Journal of Digital Earth. 1(1):119-129.

- Vickery K, Eckardt F (2013). Dust emission controls on the lower Kuiseb River valley, Central Namib. Aeolian Research. 10(3):125-133.

- Walker AL, Liu M, Miller SD, Richardson KA, Westphal DL (2009). Development of a dust source database for mesoscale forecasting in Southwest Asia. Geophysical Research. 114(18):1-24.

- Wang X, Xia D, Wang T, Xue X, Li J (2008). Dust sources in arid and semiarid China and southern Mongolia: impacts of geomorphological setting and surface materials. Geomorphology. 97(3-4):583-600.

- Zobeck T, Baddock M, Pelt R, Tatarko J, Acosts-Martinez V (2013). Soil property effects on wind erosion of organic soils. Aeolian Research. 10:43-51.

- Zoljoodj M, Didevarasl A, Saadatabadi AR (2013). Dust Events in the Western Parts of Iran and the Relationship with Drought Expansion over the Dust-Source Areas in Iraq and Syria. Atmospheric and Climate Sciences. 3(3):321-336.
East with used remote sensing. Journal of Climatology Research. 7(2):57-72. [Persian]

- Lee J, Baddock M, Mbuh M, Gill Th (2012). Geomorphic and land cover characteristics of aeolian dust sources in West Texas and eastern New Mexico, USA. Aeolian Research. 3(4):459-466.

- Lee J, Gill T, Mulligan K, Acosta MD, Perez A (2009). Land use/land cover and point sources of the 15 December 2003 dust storm in southwestern North America. Geomorphology. 105(1-2):18-27.

- Lim JY, Chun Y (2006). The characteristics of Asian dust events in Northeast Asia during the springtime from 1993 to 2004. Global and Planetary Change. 52(1-4):231247.

- Lindley TT, Vitale JD, Burgett WS, Beierle MJ (2011). Proximity meteorological observations for wind-driven grassland wildfire start on the southern High Plains. Severe Storms Meteorology. 6(1):1-27.

- Maurer T, Herrmann L, Stahr K (2009). The effect of surface variability factors on wind erosion susceptibility: A field study in SW Niger. Plant Nutrition and Soil Science. 172(6):798-807.

- Miller ME, Bowker MA, Reynolds RL, Goldstein HL (2012). Post-fire land treatments and wind erosion lessons from the Milford Flat Fire, UT, USA. Aeolian Research. 7(4):29-44.

- Moridnejad A, Karimi N, Ariya P (2015). Newly desertified regions in Iraq and its surrounding areas: Significant novel sources of global dust particles. Journal of Arid Environments. 116:1-10.

- Mosavi Bayghi M, Ashraf B (2012). The study of synoptic patterns that caused autumn and winter droughts in Khorasan Razavi Province. Water and Soil Conservation Research. 18(4):167-184. [Persian]

- Parajuli Sp, Zender CS (2017). Connecting geomorphology to dust emission through highresolution mapping of global land cover and sediment supply. Aeolian Research. 27:47-65.

- Pourghasemi HR, Kerle N (2016). Random forests and evidential belief function-based landslide susceptibility assessment in Western Mazandaran Province, Iran. Environmental Earth Sciences. 75(3):1-17.

- Pourhashemi S, Boroghani M, Zanganeh Asadi MA, AmirAhmadi A (2015). Analysis relation of vegetation cover on the number of dust event in Khorasan Razavi using geographic information system and remote sensing. RS \& GIS for Natural Resources. 6(4):33-45. [Persian]

- Prospero JM, Ginoux P, Torres O, Nicholson SE, Gill TE (2002). Environmental characterization of global sources of atmospheric soil dust identified with the Nimbus 7 total ozone mapping spectrometer absorbing aerosol product. Reviews of Geophysics. 40(1):2-31.

- Rashki A, Kaskaoutis DG, Goudie AS, Kahn RA (2013). 